\title{
Role of nuclear factor (erythroid-derived 2)-like 2 in the age-resistant properties of the glaucoma trabecular meshwork
}

\author{
JINTAO CHENG ${ }^{*}$, JIAMEI LIANG $^{*}$ and JINZE QI \\ Department of Ophthalmology, Yishui Central Hospital, Linyi, Shandong 276400, P.R. China
}

Received September 30, 2015; Accepted January 26, 2017

DOI: $10.3892 /$ etm.2017.4543

\begin{abstract}
Glaucoma is a major cause of irreversible blindness. Nuclear factor (erythroid-derived 2)-like 2 (Nrf2) regulates the expression of numerous antioxidants within cells and is therefore a focus of current ophthalmic research. To determine the roles of Nrf2 in mediating the glaucoma trabecular meshwork (GTM), the present study evaluated the levels of Nrf2 expression in GTM and human trabecular meshwork (HTM) cells by reverse-transcription-quantitative polymerase chain reaction and western blot analysis. It was principally observed that Nrf2 expression was downregulated in GTM cells. In addition, to determine the influence of $\mathrm{Nrf2}$ on the apoptosis and proliferation of GTM and HTM cells, transfection assays and western blotting were performed to evaluate the expression of apoptosis-related proteins. The results of the current study indicated that Nrf2 may promote viability and reduce apoptosis in GTM and HTM cells. Collectively, these data suggest that Nrf2 may be a novel therapeutic target to treat glaucoma.
\end{abstract}

\section{Introduction}

Glaucoma is a major cause of blindness, characterized by progressive axonal pathology and death of retinal ganglion cells, leading to structural changes in the optic nerve head and irreversible vision loss. As a result, glaucoma is now classified within a group of chronic neurodegenerative conditions that collectively, are the leading cause of irreversible blindness worldwide (1-6). As indicated by glaucoma epidemiological surveys, primary open-angle and angle-closure glaucoma occur in the majority of patients with glaucoma (7-9). A number of hypotheses have been proposed regarding the pathogenesis of glaucoma, however there is currently no hypothesis that

Correspondence to: Dr Jintao Cheng, Department of Ophthalmology, Yishui Central Hospital, 17 Jiankang Road, Yishui County, Linyi, Shandong 276400, P.R. China

E-mail: chengjintao9339@126.com

\section{${ }^{*}$ Contributed equally}

Key words: glaucoma trabecular meshwork, nuclear factor (erythroid-derived 2)-like 2, cell apoptosis, cell viability fully explains the pathological changes occurring. Although the mechanisms underlying glaucoma are not well understood, it has been established that glaucoma does not result from a single pathological mechanism, but rather a combination of pathways influenced by genes, age and environment (10-18). Despite this, there remain many unsolved problems, such as the effect of nuclear transcription factor regulation in glaucoma, that warrant further study (19).

The role of trabecular meshwork cells, including their mechanisms of apoptosis, in the pathogenesis of glaucoma is a current focus of research. Previous studies have documented that trabecular meshwork endothelial cells may directly alter the composition of the extracellular matrix during oxidative stress, resulting in elevated intraocular pressure (IOP) and glaucoma (20-24). Nuclear factor (erythroid-derived 2)-like 2 (Nrf2) is a central regulator of cellular oxidation reactions and serves a key role in cell defense mechanisms against oxidative stress (25-29). However, the expression and functions of Nrf-2 in trabecular meshwork cells are currently unknown. Therefore, the present study evaluated the functions of Nrf-2 in glaucoma.

Using reverse transcription-quantitative polymerase chain reaction (RT-qPCR) and western blot analysis, the levels of Nrf2 in glaucoma trabecular meshwork (GTM) cells were assessed. It was observed that Nrf2 expression was downregulated in GTM cells, relative to human trabecular meshwork (HTM) cells. Results from a transfection assay demonstrated that Nrf2 overexpression markedly increased the viability of GTM and HTM cells, while significantly decreasing their rates of apoptosis. Furthermore, western blot analysis indicated that Nrf2 regulated the expression of apoptosis-related proteins. Collectively, these results suggest an association between $\mathrm{Nrf}-2$ expression and glaucoma, thus offering a potential therapeutic target for the treatment of glaucoma.

\section{Materials and methods}

Cell culture. HTM and GTM cells were kindly provided by Yishui Central Hospital (Shandong, China). HTM and GTM cells were grown in an adherent cell culture with Dulbecco's modified Eagle medium (DMEM) supplemented with $20 \%$ fetal bovine serum (both Gibco; Thermo Fisher Scientific, Inc., Waltham, MA, USA) at $37^{\circ} \mathrm{C}, 5 \% \mathrm{CO}_{2}$ and $100 \%$ humidity in a controlled incubator. Cells were subcultured in a humidified 
$5 \% \mathrm{CO}_{2}$ incubator at $37^{\circ} \mathrm{C}$ when they reached a confluence of $70-90 \%$, then washed twice with D-Hanks solution.

Plasmid and small interfering RNA (siRNA) transfection. Plasmids expressing siRNA targeting Nrf2 (siNrf2), overexpressing Nrf2 and control siRNA (non-silencing) were synthesized by Shanghai GenePharma Co., Ltd. (Shanghai, China). Cells were seeded in 6-well plates and cultured in DMEM overnight at $37^{\circ} \mathrm{C}$ in a humidified atmosphere of $95 \%$ air and $5 \% \mathrm{CO}_{2}$. Subsequently, cell transfections were conducted using Lipofectamine ${ }^{\circledR} 2000$ reagent (Invitrogen; Thermo Fisher Scientific, Inc.), according to the manufacturer's protocol.

$R T-q P C R$. Total mRNA was isolated from the transfected cell groups and untransfected cells, as previously described (30). Complementary DNA (cDNA) was produced by reverse transcription using an iScript ${ }^{\mathrm{TM}}$ cDNA Synthesis kit (Bio-Rad Laboratories, Inc., Hercules, CA, USA), according to the manufacturer's instructions. Levels of mRNA expression were measured by SYBR-Green-based qPCR using a SYBR ${ }^{\circledR}$ Green Master mix (Thermo Fisher Scientific, Inc.), according to the manufacturer's protocol. The primer sequences used were as follows: Nrf2, forward 5'-ATGGATTTGATTGAC ATACTTT-3' and reverse 5'-ACTGAGCCTGATTAGTAG CAAT-3'; and GAPDH, forward 5'-TCCTGCACCACCAAC TGCTTAG-3' and reverse 5'-ATGGGCAGTGATGGCATG GACT-3'. qPCR conditions were as follows: Initial denaturation was performed at $95^{\circ} \mathrm{C}$ for $15 \mathrm{sec}$, followed by 30 cycles of $95^{\circ} \mathrm{C}$ for $30 \mathrm{sec}, 61^{\circ} \mathrm{C}$ for $5 \mathrm{sec}, 72^{\circ} \mathrm{C}$ for $15 \mathrm{sec}$, and a final extension at $72^{\circ} \mathrm{C}$ for $10 \mathrm{~min}$. GAPDH gene expression was used as a reference. mRNA expression levels were quantified using the $2^{-\Delta \Delta \mathrm{Cq}}$ method (31).

Cell viability assay. The transfected HTM and GTM cells during the logarithmic growth phase were cultured in 96-well plates with DMEM $\left(5 \times 10^{4}\right.$ cells $\left./ \mathrm{ml}\right)$ at $37^{\circ} \mathrm{C}$. Four repeat cultures were completed for each cell transfection group. Following culture for 24, 48, 72 and 96 h, $20 \mu$ fresh DMEM supplemented with $0.5 \mathrm{mg} / \mathrm{ml}$ MTT (Sigma-Aldrich; Merck KGaA, Darmstadt, Germany) was added to each well and incubated for $4 \mathrm{~h}$ at $37^{\circ} \mathrm{C}$. A total of $200 \mu \mathrm{l}$ dimethyl sulfoxide (DMSO; Sigma-Aldrich; Merck KGaA) was added to each well. Cells incubated with just DMSO were used as controls. Optical densities of each well were subsequently measured at an absorbance of $492 \mathrm{~nm}$.

Apoptosis assay. Cells transfected with siNrf 2 for $28 \mathrm{~h}$ were seeded in a 6 -well plate at a density of $2 \times 10^{5}$ cells/well in DMEM. Cell apoptosis was assayed using the FITC Annexin V Apoptosis Detection kit (Beijing Biosynthesis Biotechnology Co., Ltd., Beijing, China), according to the manufacturer's instructions. Stained cells were analyzed with a fluorescence-activated cell sorting Calibur flow cytometer (BD Biosciences, San Jose, CA, USA). The data were analyzed using FlowJo v. 9.0 software (Tree Star, Inc., Ashland, OR, USA). The percentage of total apoptotic events was defined as the sum of cells in the early (Annexin V positive/PI negative) and late (Annexin V positive/PI positive) stages of apoptosis, as described previously (32).

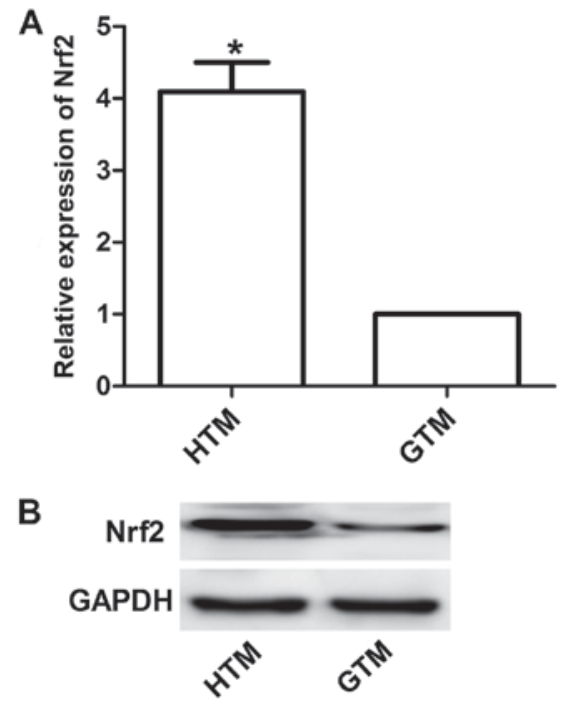

Figure 1. Expression of Nrf2 in HTM and GTM cells. (A) Expression of Nrf2 mRNA in GTM and HTM cells relative to GAPDH. (B) Nrf2 protein expression levels in GTM and HTM cells according to western blotting. ${ }^{*} \mathrm{P}<0.05$ vs. GTM. Nrf2, nuclear factor (erythroid-derived 2)-like 2; GTM, glaucoma trabecular meshwork; HTM, human (non-glaucoma) trabecular meshwork.

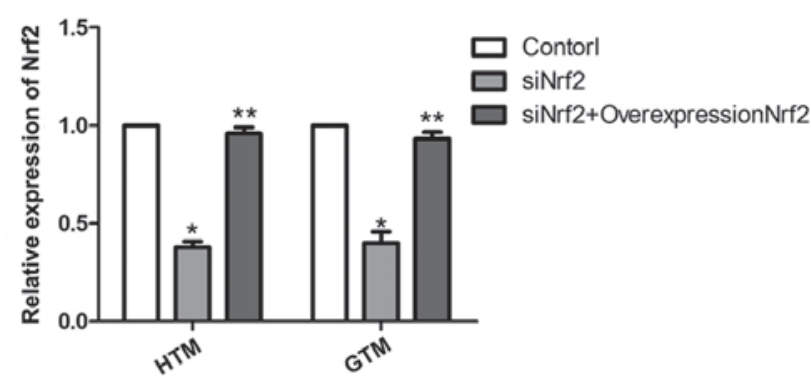

Figure 2. Regulation of Nrf2 expression in HTM and GTM cells. Results of reverse transcription-quantitative polymerase chain reaction demonstrated that siNrf2 successfully downregulated Nrf2 expression, which was subsequently rescued by Nrf2 overexpression. mRNA expression levels were measured relative to GAPDH. ${ }^{*} \mathrm{P}<0.05$ vs. untransfected control, ${ }^{* *} \mathrm{P}<0.01$ vs. siNrf2 transfectants. Nrf2, nuclear factor (erythroid-derived 2)-like 2; GTM, glaucoma trabecular meshwork; HTM, human (non-glaucoma) trabecular meshwork; siNrf2, Nrf2 small interfering RNA.

Western blot analysis. Protein was extracted from cells transfected with Nrf2, siNrf2 or control using radioimmunoprecipitation assay buffer (Beyotime Institute of Biotechnology, Shanghai, China). Protein samples (30 $\mu \mathrm{g} /$ lane) were separated by $10-12 \%$ SDS-PAGE, blotted onto polyvinylidene difluoride membranes, blocked in 5\% fresh non-fat milk in phosphate-buffered saline (PBS)-Triton X-100 (0.1\% Triton in PBS) for $1 \mathrm{~h}$ at room temperature. Subsequently, the membranes were incubated with primary antibodies: Nrf2 (ab31163), BCL2-Associated X (Bax; ab32503), B-cell lymphoma (BCL)-2 (ab32124), p53 (ab1101), phospho (p)-p53 (ab1431) and GAPDH (ab8245; all Abcam, Cambridge, USA; all 1:1,000) overnight at $4^{\circ} \mathrm{C}$. Thereafter, membranes were incubated with corresponding horseradish peroxidase-conjugated secondary antibodies (ab6721; ab6788; 1:5,000; Abcam) for $1 \mathrm{~h}$ at room temperature. Immunoreactive protein bands were developed by enhanced chemiluminescence western blotting substrate (Pierce; Thermo Fisher Scientific, Inc.) and analyzed using 

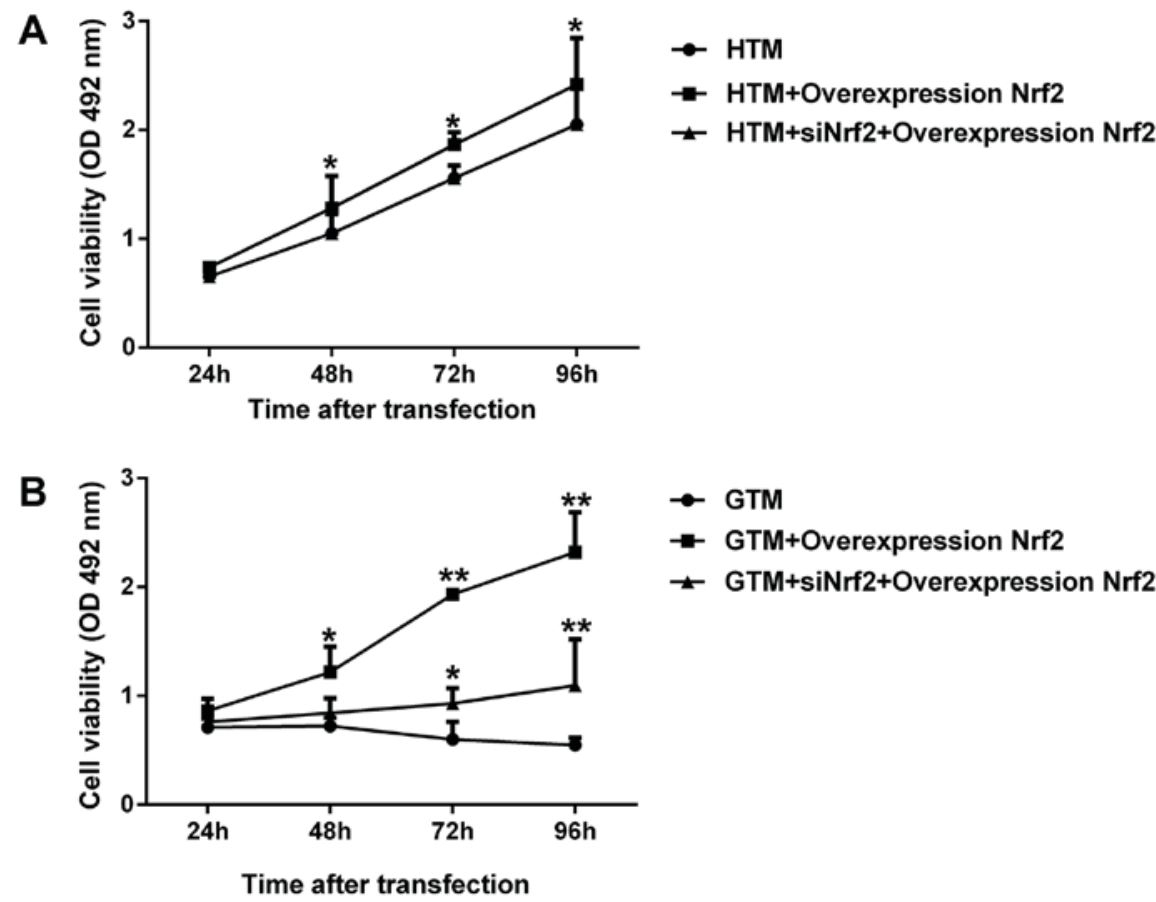

$\rightarrow$ GTM

$\rightarrow$ - GTM+Overexpression Nrf2

- GTM+siNrf2+Overexpression Nrf2

Figure 3. Viability of (A) HTM and (B) GTM cells transfected with Nrf2 overexpression plasmid or siNrf2. After 48 h, viability of untransfected GTM cells decreased, while all other cell groups remained in a proliferative phase throughout the assay period ( $96 \mathrm{~h})$. " $\mathrm{P}<0.05$ and ${ }^{* *} \mathrm{P}<0.01$ vs. the respective non-transfected control. Nrf2, nuclear factor (erythroid-derived 2)-like 2; GTM, glaucoma trabecular meshwork; HTM, human (non-glaucoma) trabecular meshwork; siNrf2, Nrf2 small interfering RNA; OD, optical density.

Image Gauge v. 4.0 software (FujiFilm Science Lab, Tokyo, Japan).

Statistical analysis. All experiments were repeated three times. Results are presented as the mean \pm standard deviation. Statistical analyses were performed using SPSS 19.0 software (IBM SPSS, Armonk, NY, USA). P-values were calculated using one-way analysis of variance and $\mathrm{P}<0.05$ was considered to indicate a statistically significant result.

\section{Results}

Nrf2 expression is upregulated in HTM cells. Western blotting and RT-qPCR were performed to detect Nrf2 expression. Results demonstrated that the expression of Nrf2 was significantly upregulated in HTM cells compared with GTM cells ( $\mathrm{P}<0.05$; Fig. 1). This was demonstrated to be significant at the mRNA level by subsequent analysis of HTM and GTM cells transfected with siNrf2 to downregulate Nrf2 expression. As depicted in Fig. 2, the mRNA expression levels of Nrf2 were effectively regulated by $\operatorname{siNrf2}$, with significant decreases in Nrf2 observed in siNrf2 transfectants compared with the control $(\mathrm{P}<0.05)$. In addition, the mRNA expression levels of Nrf2 overexpression plasmid together with siNrf2 were significantly upregulated in HTM and GTM cells compared with cells transfected with siNrf2 alone $(\mathrm{P}<0.01)$.

Nrf2 increases the viability of HTM and GTM cells. To determine the effect of Nrf2 expression on GTM and HTM cell viability, cells were transfected with $\mathrm{Nrf} 2$ overexpression

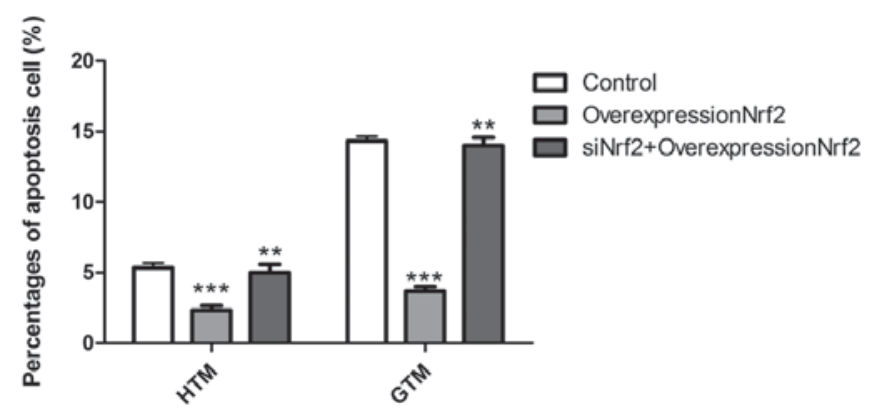

Figure 4. Effect of siNrf2 together with overexpression of Nrf2, and overexpression of Nrf2 on cell apoptosis in HTM and GTM cells. Results from an Annexin V/propidium iodide staining assay demonstrated that overexpression of Nrf2 significantly reduced apoptosis in GTM and HTM cells. This effect was subsequently rescued by transfection with siNrf2. ${ }^{* * *} \mathrm{P}<0.001$ vs. untransfected control, ${ }^{* *} \mathrm{P}<0.01$ vs. Nrf2 overexpression plasmid transfectants. Nrf2, nuclear factor (erythroid-derived 2)-like 2; GTM, glaucoma trabecular meshwork; HTM, human (non-glaucoma) trabecular meshwork; siNrf2, Nrf2 small interfering RNA.

plasmid alone and Nrf2 overexpression together with siNrf2. As demonstrated in Fig. 3A, regulation of Nrf2 expression significantly enhanced the viability of GTM and HTM cells. In HTM cells, overexpression Nrf2 significantly improved cell viability $(\mathrm{P}<0.05)$, while Nrf2 overexpression together with siNrf2 demonstrated no significant change compared with the respective non-transfected control. In GTM cells, overexpression of Nrf2 and Nrf2 overexpression together with siNrf2 significantly promoted cell viability $(\mathrm{P}<0.05$; Fig. $3 \mathrm{~B})$. These results indicated that the greatest increases in GTM and HTM 
A

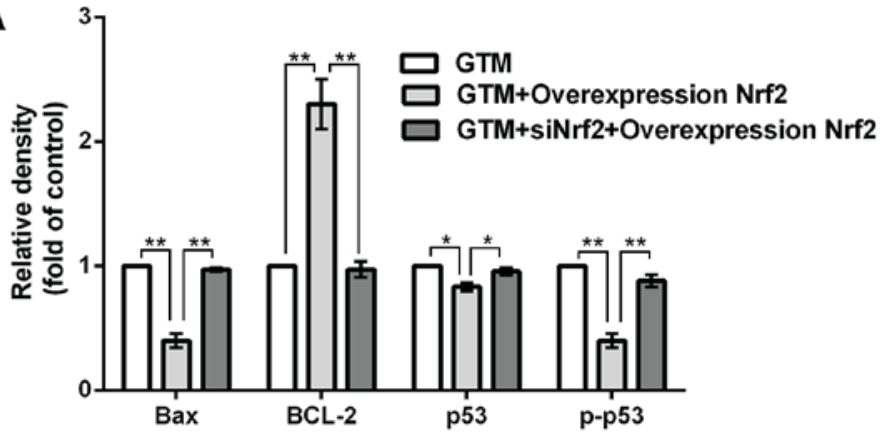

B

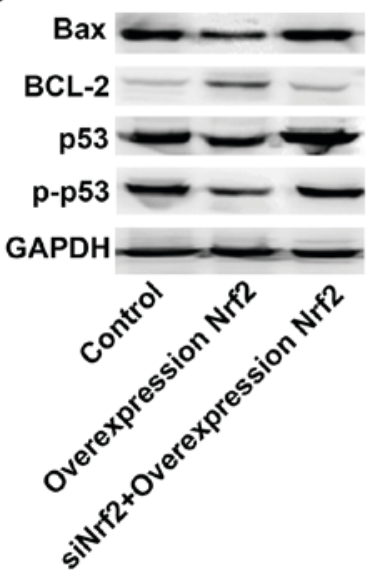

Figure 5. Effect of Nrf2 on apoptosis-related protein expression in GTM cells. Western blotting assay followed by densitometric analysis demonstrated that Nrf2 regulated the expression of apoptosis-related proteins. ${ }^{*} \mathrm{P}<0.05$ and ${ }^{* *} \mathrm{P}<0.01$. GTM, glaucoma trabecular meshwork.

cell viability were observed in Nrf2 overexpression plasmid alone. Interestingly, the viability of untransfected GTM cells decreased after $48 \mathrm{~h}$, while all other cell groups remained in a proliferative phase throughout the 96 -h assay period.

Nrf2 decreases the apoptotic rate of HTM and GTM cells. To determine the effect of Nrf2 expression on GTM and HTM cell apoptosis, cells were transfected with Nrf2 overexpression plasmid alone and in combination with siNrf2. As depicted in Fig. 4, overexpression of Nrf2 significantly decreased the rate of apoptosis in GTM and HTM cells $(\mathrm{P}<0.001)$. This effect was most prominent in GTM cells, due to their higher starting rate of apoptosis, when compared to HTM cells. In turn, transfection overexpression Nrf2 together with siNrf2 significantly reversed the lowered rate of apoptosis than Nrf2 overexpressing cells $(\mathrm{P}<0.01)$. These results suggest that $\mathrm{Nrf} 2$ may regulate GTM and HTM cells through induction of apoptosis.

Nrf2 regulates the expression of apoptosis-related proteins. BCL-2, bcl-2-like protein 4 (Bax), tumor suppressor protein $\mathrm{p} 53$ and phosphorylated (p)-p53 are all apoptosis-related proteins, with BCL-2 considered to be a key anti-apoptotic factor $(33,34)$. Therefore, to determine whether Nrf2 regulates the expression of apoptosis-related proteins, levels of BCL-2, Bax, p53 and p-p53 were evaluated by western blotting and densitometric analysis following Nrf2 overexpression in GTM cells. As depicted in Fig. 5, overexpression of Nrf2 significantly upregulated BCL-2 $(\mathrm{P}<0.01)$, while significantly downregulating Bax, p53 and p-p53 expression $(P<0.01)$, relative to control cells. In turn, transfection with siNrf2 significantly reversed the altered expression of BCL-2 $(\mathrm{P}<0.01), \mathrm{Bax}(\mathrm{P}<0.01), \mathrm{p} 53(\mathrm{P}<0.05)$ and p-p53 $(\mathrm{P}<0.01)$ compared with Nrf2 overexpressing cells.

\section{Discussion}

Glaucoma is a retinal neuropathy that can lead to permanent blindness, and is associated with elevated intraocular pressure (IOP), due to fibrosis and degeneration of the trabecular meshwork (35). It is the second leading cause of progressive vision loss and is expected to affect 80 million people worldwide by 2020 (36). The etiology of glaucoma is complex and is generally considered to arise due to a combination of factors, including genes, age and environmental factors (37).

Several genes have been identified as contributing factors (38). Although numerous studies have been conducted, the mechanisms underlying glaucoma remain unknown. Due to its location, the trabecular meshwork serves a key role in aqueous fluid circulation, thus dysfunction of the trabecular meshwork may be a key contributing factor in the onset of primary open-angle glaucoma (39).

In addition, the trabecular meshwork is considered to be involved in the regulation of IOP, due to observations that glaucoma trabecular meshwork cells undergo increased rates of apoptosis in a high IOP state (40). Nrf2 is a key transcription factor in the regulation of antioxidant and Phase II detoxification gene expression, and is activated by oxidative stress and the presence of electrophiles. It has been observed that Nrf2 exerts protective effects in both normal and cancer cells during cell stress, thereby serving key roles in the development of cancer, including gastric, and skin cancer (41-45). It is considered that Nrf2 protects cells from oxidative stress through overproduction of antioxidants and detoxification proteins $(46,47)$. Ran et al (48) demonstrated that the regulatory effects of $\mathrm{Nrf} 2$ on microRNA-29b expression influenced the proliferation of Tenon's capsule fibroblasts obtained from patients with glaucoma. Sun et al (49) also observed that NRF2 may determine the therapeutic response of hepatocellular carcinoma cells to ferroptosis-targeted therapies.

To determine the underlying mechanisms regarding the effects of Nrf2 on trabecular meshwork cells, particularly during glaucoma, the present study evaluated cell behaviors associated with Nrf2 expression. Levels of Nrf2 in HTM and GTM cells were evaluated by western blotting and RT-qPCR, with observations that Nrf2 was downregulated in GTM cells relative to HTM cells. To elucidate the role of Nrf2 in GTM cell apoptosis, levels of Nrf2 were subsequently regulated using siNrf2 and overexpression plasmid, and it was observed that overexpression of Nrf2 stimulated proliferation and inhibited apoptosis in GTM and HTM cells. 
The current study demonstrated that overexpression of Nrf2 had regulatory effects on the expression of apoptosis-related proteins. Upregulation of the anti-apoptotic factor BCL-2, and downregulation of Bax, p53 and p-p53 were all observed following Nrf2 overexpression. Collectively, these findings suggest that Nrf2 serves a key role in the regulation of trabecular meshwork cells in glaucoma. Specifically, overexpression of Nrf2 may attenuate apoptosis of GTM cells by regulating apoptosis-related proteins.

In conclusion, the present results indicate a novel role of Nrf2 within trabecular meshwork cells during glaucoma and may offer insight into the underlying mechanisms of glaucoma. It was principally demonstrated that $\mathrm{Nrf} 2$ may have regulatory effects on trabecular meshwork cell apoptosis, suggesting that $\mathrm{Nrf} 2$ is a potential therapeutic target in the prevention and treatment of glaucoma.

\section{References}

1. Akram MU, Tariq A, Khalid S, Javed MY, Abbas S and Yasin UU: Glaucoma detection using novel opticdisc localization, hybrid feature set and classification techniques. Australas Phys Eng Sci Med 38: 643-655, 2015

2. Hua Z, Fang Q, Sha X, Yang R and Hong Z: Role of retinal nerve fiber layer thickness and optic disk measurement by OCT on early diagnosis of glaucoma. Eye Sci 30: 7-12, 2015.

3. Pinchuk L, Riss I, Batlle JF, Kato YP, Martin JB, Arrieta E, Palmberg P, Parrish RK II, Weber BA, Kwon Y and Parel JM: The development of a micro-shunt made from poly (styrene-block-isobutylene-block-styrene) to treat glaucoma. J Biomed Mater Res B Appl Biomater 105: 211-221, 2017.

4. Wilson GN, Inman DM, Denger-Crish CM, Smith MA and Crish SD: Early pro-inflammatory cytokine elevations in the DBA/2J mouse model of glaucoma. J Neuroinflammation 12 : $176,2015$.

5. Nuschke AC, Farrell SR, Levesque JM and Chauhan BC: Assessment of retinal ganglion cell damage in glaucomatous optic neuropathy: Axon transport, injury and soma los. Exp Eye Res 141: 111-124, 2015.

6. Vidal-Sanz M, Salinas-Navarro M, Nadal-Nicolás FM, Alarcón-Martínez L, Valiente-Soriano FJ, de Imperial JM, Avilés-Trigueros M, Agudo-Barriuso M and Villegas-Pérez MP: Understanding glaucomatous damage: Anatomical and functional data from ocular hypertensive rodent retinas. Prog Retin Eye Res 31: 1-27, 2012.

7. Baskaran M, Foo RC, Cheng CY, Narayanaswamy AK, Zheng YF, Wu R, Saw SM, Foster PJ, Wong TY and Aung T: The prevalence and types of glaucoma in an urban Chinese population: The Singapore Chinese eye study. JAMA Ophthalmol 133 874-880, 2015.

8. Song W, Shan L, Cheng F, Fan P, Zhang L, Qu W, Zhang Q nd Yuan H: Prevalence of glaucoma in a rural northern China adult population: A population-based survey in kailu county, inner mongolia. Ophthalmology 118: 1982-1988, 2011.

9. Tham YC, Li X, Wong TY, Quigley HA, Aung T and Cheng CY: Global prevalence of glaucoma and projections of glaucoma burden through 2040: A systematic review and meta-analysis. Ophthalmology 121: 2081-2090, 2014

10. Wostyn P, Van Dam D, Audenaert K, Killer HE, De Deyn PP and De Groot V: A new glaucoma hypothesis: A role of glymphatic system dysfunction. Fluids Barriers CNS 12: 16, 2015.

11. Cuchra M, Markiewicz L, Mucha B, Pytel D, Szymanek K, Szemraj J, Szaflik J, Szaflik JP and Majsterek I: The role of base excision repair in the development of primary open angle glaucoma in the Polish population. Mutat Res 778: 26-40, 2015.

12. Mousa A, Kondkar AA, Al-Obeidan SA, Azad TA, Sultan T, Osman E and Abu-Amero KK: Association of total antioxidants level with glaucoma type and severity. Saudi Med J 36: 671-677, 2015.

13. Almasieh M, Wilson AM, Morquette B, Cueva Vargas JL and Di Polo A: The molecular basis of retinal ganglion cell death in glaucoma. Prog Retin Eye Res 31: 152-181, 2012.
14. Lebrun-Julien F and Di Polo A: Molecular and cell-based approaches for neuroprotection in glaucoma. Optom Vis Sci 85: 417-424, 2008

15. Doucette LP, Rasnitsyn A, Seifi M and Walter MA: The interactions of genes, age, and environment in glaucoma pathogenesis. Surv Ophthalmol 60: 310-326, 2015.

16. Liu P, Zhang M, Shoeb M, Hogan D, Tang L, Syed MF, Wang CZ, Campbell GA and Ansari NH: Metal chelator combined with permeability enhancer ameliorates oxidative stress-associated neurodegeneration in rat eyes with elevated intraocular pressure. Free Radic Biol Med 69: 289-299, 2014

17. Vohra R, Tsai JC and Kolko M: The role of inflammation in the pathogenesis of glaucoma. Surv Ophthalmol 58: 311-320, 2013.

18. Nickells RW, Howell GR, Soto I and John SW: Under pressure: Cellular and molecular responses during glaucoma, a common neurodegeneration with axonopathy. Annu Rev Neurosci 35: 153-179, 2012.

19. Motallebipour M, Rada-Iglesias A, Jansson M and Wadelius C: The promoter of inducible nitric oxide synthase implicated in glaucoma based on genetic analysis and nuclear factor binding. Mol Vis 11: 950-957, 2005.

20. Itakura T, Peters DM and Fini ME: Glaucomatous MYOC mutations activate the IL-1/NF- $\kappa \mathrm{B}$ inflammatory stress response and the glaucoma marker SELE in trabecular meshwork cells. Mol Vis 21: 1071-1084, 2015.

21. Chen WS, Cao Z, Krishnan C and Panjwani N: Verteporfin without light stimulation inhibits YAP activation in trabecular meshwork cells: Implications for glaucoma treatment. Biochem Biophys Res Commun 466: 221-225, 2015.

22. Pattabiraman PP and Rao PV: Hic-5 regulates actin cytoskeletal reorganization and expression of fibrogenic markers and myocilin intrabecular meshwork cells. Invest Ophthalmol Vis Sci 56: 5656-5669, 2015.

23. Stothert AR, Fontaine SN, Sabbagh JJ and Dickey CA: Targeting the ER-autophagy system in the trabecular meshwork to treat glaucoma. Exp Eye Res 144: 38-45, 2016.

24. Morgan JT, Raghunathan VK, Chang YR, Murphy CJ and Russell P: The intrinsic stiffness of human trabecular meshwork cells increases with senescence. Oncotarget 6: 15362-15374, 2015.

25. Sachdeva MM, Cano M and Handa JT: Nrf2 signaling is impaired in the aging RPE given an oxidative insult. Exp Eye Res 119: 111-114, 2014.

26. Ruiz S, Pergola PE, Zager RA and Vaziri ND: Targeting the transcription factor Nrf2 to ameliorate oxidative stress and inflammation in chronic kidney disease. Kidney Int 83: 1029-1041, 2013.

27. Xu Z, Wei Y, Gong J, Cho H, Park JK, Sung ER, Huang H, Wu L, Eberhart C, Handa JT, et al: Nrf2 plays a protective role in diabetic retinopathy in mice. Diabetologia 57: 204-213, 2014.

28. Ko SY, Chang SS, Lin IH and Chen HI: Suppression of antioxidant Nrf-2 and downstream pathway in $\mathrm{H} 9 \mathrm{c} 2$ cells by advanced glycation end products (AGEs) via ERK phosphorylation. Biochimie 118: 8-14, 2015.

29. Njayou FN, Amougou AM, Fouemene Tsayem R, Njikam Manjia J, Rudraiah S, Bradley B, Manautou JE and Fewou Moundipa P: Antioxidant fractions of Khaya grandifoliola C.DC. and Entada africana Guill. et Perr. induce nuclear translocation of Nrf2 in HC-04 cells. Cell Stress Chaperones 20: 991-1000, 2015.

30. Fransson L, Rosengren V, Saha TK, Grankvist N, Islam T, Honkanen RE, Sjöholm A and Ortsäter H: Mitogen-activated protein kinases and protein phosphatase 5 mediate glucocorticoid-induced cytotoxicity in pancreatic islets and $\beta$-cells. Mol Cell Endocrinol 383: 126-136, 2014.

31. Livak KJ and Schmittgen TD: Analysis of relative gene expression data using real-time quantitative PCR and the 2(-Delta Delta C(T)) method. Methods 25: 402-408, 2001.

32. Jung HS, Rajasekaran N, Song SY, Kim YD, Hong S, Choi HJ, Kim YS, Choi JS, Choi YL and Shin YK: Human papillomavirus E6/E7-specific siRNA potentiates the effect of radiotherapy for cervical cancer in vitro and in vivo. Int J Mol Sci 16: 12243-12260, 2015.

33. Qin YU, Wang H, Liu ZY, Liu J and Wu JZ: Realgar quantum dots induce apoptosis and necrosis in HepG2 cells through endoplasmic reticulum stress. Biomed Rep 3: 657-662, 2015.

34. Lee JY, Jee SB, Park WY, Choi YJ, Kim B, Kim YH, Jun do Y and Kim YH: Tumor suppressor protein p53 promotes 2-methoxyestradiol-induced activation of Bak and Bax, leading to mitochondria-dependent apoptosis in human colon cancer HCT116 cells. J Microbiol Biotechnol 24: 1654-1663, 2014 
35. Wordinger RJ, Sharma T and Clark AF: The role of TGF- $\beta 2$ and bone morphogenetic proteins in the trabecular meshwork and glaucoma. J Ocul Pharmacol Ther 30: 154-162, 2014

36. Chen X, Xu Y, Duan L, Zhang Z, Wong DWK and Liu J: Multiple ocular diseases detection by graph regularized multi-label learning. 2014.

37. Casson RJ, Chidlow G, Ebneter A, Wood JP, Crowston J and Goldberg I: Translational neuroprotection research in glaucoma: A review of definitions and principles. Clin Exp Ophthalmol 40: 350-357, 2012.

38. Janulevičiene I, Ehrlich R, Siesky B, Nedzelskienė I and Harris A: Evaluation of hemodynamic parameters as predictors of glaucoma progression. J Ophthalmol 2011: 164320, 2011.

39. Crabb JW, Yuan X, Crabb JS, Putliwala TM, Clark AF and Bollinger KE: Quantitative proteomic studies implicate mitochondrial dysfunction in the trabecular meshwork in glaucoma pathology. 2011.

40. Tamm ER, Braunger BM and Fuchshofer R: Intraocular pressure and the mechanisms involved in resistance of the aqueous humor flow in the trabecular meshwork outflow pathways. Prog Mol Biol Transl Sci 134: 301-314, 2015.

41. Zheng H, Nong $\mathrm{Z}$ and Lu G: Correlation between nuclear factor E2-related factor 2 expression and gastric cancer progression. Med Sci Monit 21: 2893-2899, 2015.

42. Leone A, Roca MS, Ciardiello C, Terranova-Barberio M, Vitagliano C, Ciliberto G, Mancini R, Di Gennaro E, Bruzzese F and Budillon A: Vorinostat synergizes with EGFR inhibitors in NSCLC cells by increasing ROS via up-regulation of the major mitochondrial porin VDAC1 and modulation of the c-Myc-NRF2-KEAP1 pathway. Free Radic Biol Med 89: 287-299, 2015.
43. Wang D, Ma Y, Yang X, Xu X, Zhao Y, Zhu Z, Wang X, Deng H, Li C, Gao F, et al: Hypermethylation of the Keapl gene inactivates its function, promotes Nrf2 nuclear accumulation, and is involved in arsenite-induced human keratinocyte transformation. Free Radic Biol Med 89: 209-219, 2015.

44. Rushworth SA, Bowles KM and MacEwan DJ: High basal nuclear levels of Nrf2 in acute myeloid leukemia reduces sensitivity to proteasome inhibitors. Cancer Res 71: 1999-2009, 2011.

45. Ohnuma T, Anzai E, Suzuki Y, Shimoda M, Saito S, Nishiyama T, Ogura K and Hiratsuka A: Selective antagonization of activated Nrf2 and inhibition of cancer cell proliferation by procyanidins from Cinnamomi Cortex extract. Arch Biochem Biophys 585: 17-24, 2015.

46. Pastorek M, Müller P and Vojtěšek B: Nrf2- two faces of antioxidant system regulation. Klin Onkol 28 (Suppl 2): 2S26-2S31, 2015 (In Czech).

47. Tertil M, Golda S, Skrzypek K, Florczyk U, Weglarczyk K, Kotlinowski J, Maleszewska M, Czauderna S, Pichon C, Kieda C, et al: Nrf2-heme oxygenase-1 axis in mucoepidermoid carcinoma of the lung: Antitumoral effects associated with down-regulation of matrix metalloproteinases. Free Radic Biol Med 89: 147-157, 2015.

48. Ran W, Zhu D and Feng Q: TGF- $\beta 2$ stimulates Tenon's capsule fibroblast proliferation in patients with glaucoma via suppression of miR-29b expression regulated by Nrf2. Int J Clin Exp Pathol 8: 4799-4806, 2015.

49. Sun X, Ou Z, Chen R, Niu X, Chen D, Kang R and Tang D: Activation of the p62-Keap1-NRF2 pathway protects against ferroptosis in hepatocellular carcinoma cells. Hepatology 63: $173-184,2016$ 